\title{
Comparative Study of Two Different Types of Power Weeders
}

\author{
S. Leela Jyothi* , S. S. Meena and G. S. Tiwari \\ Department of Farm Machinery and Power Engineering, College of Technology and \\ Engineering, Maharana Pratap University of Agriculture and Technology, Udaipur \\ (Rajasthan), India \\ *Corresponding author
}

\section{A B S T R A C T}

\section{Keywords}

Power weeder, Hand transmitted vibration, Vibration analyser, Weeding

\section{Article Info}

Accepted:

08 December 2020 Available Online: 10 January 2021
Hand operated farm machinery produces higher amounts of vibrations, which can cause Musculoskeletal disorders like white finger syndrome and blanching of fingers. Long term exposure to this vibration leads to fatigue and discomfort that causes lower performance efficiency of the worker. Weeding is an important operation in cultivation of row crops. Large farms require weeding machinery for proper and quick removal of weeds. Otherwise, there will be a huge loss in production that raised due to the competition between weeds and the main crop for nutrients. In this study, two different types of power weeders were taken for vibration measurement. These two are different in constructional material, weight and source of power. The vibrations transmitted to hand are higher in amar power weeder during intercultural operations i.e. $17.55 \mathrm{~ms}^{-2}$ at a speed of $2800 \mathrm{rpm}$. In both the power weeders, HTV increased as the speed is increased. In BCS power weeder, there are some arrangements to dampen the vibrations. It produced only $4.85 \mathrm{~ms}^{-2}$ and $5.20 \mathrm{~ms}^{-2}$ at the speeds of $1800 \mathrm{rpm}$ and $2700 \mathrm{rpm}$ during intercultural operations respectively. Therefore, $\mathrm{BCS}$ power weeder is more comfortable to the operator.

\section{Introduction}

Agriculture is the most important sector of the Indian Economy. The production of food grains for the year 2018-19 was recorded as 285.17 million tonnes, which is slightly higher than food grain output of 285.01 million tonnes in 2017-18. This is a good symptom for the Indian economy from the agriculture sector. Proper use of mechanized inputs into agriculture has a direct and significant effect on production, productivity and profitability on agriculture farms, along with labor productivity and quality of life of people engaged in agriculture. Empirical evidence confirms that there is a strong correlation between farm mechanization and agricultural productivity. States with a greater availability of farm power show higher productivity as compared to others.

With the introduction of modern technology, ergonomics becomes essential for its successful application. The important point here is that the major benefit to the agriculture is to have safe, healthy and productive 
worker. In farm works, the fatigue and discomfort to which human beings are subjected is not only due to physical work but also to vibration and noise as well (Huang and Suggs, 1968). The vibrations acting on the human body are called human vibration and this is classified into two types. One is whole body vibration (WBV) and another one is hand-transmitted vibration (HTV). The handtransmitted vibration exposure during the operation of power weeder is greater than the recommended limit of ISO 5349 (1986).

Hand transmitted vibration of the power weeder is very severe as the handle is a cantilever beam and the power is obtained from a single cylinder diesel engine (Ying et $a l .$, 1998). This may lead to pain in the arms and shoulders, numbness, reduced grip strength, and also circulatory disorders, as well as bone, joint or muscle diseases. These effects can further give rise to sleep disturbances and reduction of efficiency at work. Therefore, there is a need to select the power weeder that transmits vibration within the permissible limit. The objective of this study was to assess the hand transmitted vibration in two different available power weeders.

\section{Theoretical consideration}

Vibration is defined as the effect of mechanical vibration on the human body. There are two major types of human vibration: hand transmitted vibration (HTV) and whole body vibration (WBV). Hand transmitted vibration is transmitted to the hands and arms through the handle while walking behind the power weeder. It is known that the vibration entering the hand contains contributions from all three measurement directions. Therefore, the measurement should preferably be made for all three directions simultaneously. Figure.1 illustrate an anatomical and basicentric coordinate system for measurement of hand transmitted vibration exposure as defined in ISO 53491(2001).

\section{Magnitude of vibration}

When the human body is in contact with a vibrating mechanical device, it is displaced about its contact position (Sanders and Mccormick, 1993). Displacement is therefore one parameter which can be used to describe the magnitude of a vibration. Although displacement, velocity and acceleration can be used for quantifying the vibration severity. Human response to vibration is highly dependent on the frequency of the vibration. As per the ISO 5349(2001) recommendations, the most important quantity used to describe the magnitude of vibration transmitted to the operator's hands is root mean square (rms) frequency weighted acceleration in $\mathrm{ms}^{-2}$ expressed as

$a_{h w}=\left[\sum_{j=1}^{n}\left(W_{h} a_{h j}\right)^{2}\right]^{1 / 2}$

Where

$a_{\text {hw }}=$ Root mean square (rms) frequency weighted acceleration

$W_{h}=$ Weighting factor for $\mathrm{j}^{\text {th }}$ one-third octave band

$a_{h j}=$ rms acceleration measured in one-third octave band used in $\mathrm{ms}^{-2}$

$\mathrm{n}=$ number of frequencies used in the octave band

The weighted value should be determined over the eight octave bands (i.e $n=8$ ) from 8 to $1000 \mathrm{~Hz}$ or over the 24 one third octave bands (i.e $n=24$ ) from 6.3 to $1250 \mathrm{~Hz}$. The one- third octave band is very common and is adopted in the ISO 5349 (2001). The 
sensitivity of body to different frequencies is different, so weighting factor for different frequency bands are defined in ISO 5349-1 (2001) which are given in the table.1. It is clear from the table that the hand-transmitted vibration is more sensitive to the frequency range of 6.3 to $31.5 \mathrm{~Hz}$.

Vector sum of the frequency weighted acceleration (Vibration total values) in three axes represents the acute effects better than does the weighted acceleration in the main axis alone. This is the vibration total value $a_{\mathrm{hv}}$ and it is defined as the rms of the three component values given below

$a_{h v=} \sqrt{\left(a_{h w x}\right)^{2}+\left(a_{h w y}\right)^{2}+\left(a_{h w z}\right)^{2}}$

Where

$a_{h v=\text { total } \mathrm{rms}}$ weighted acceleration at the handle in $\mathrm{ms}^{-2}$

$a_{\text {hwx }}=\mathrm{rms}$ weighted acceleration in $\mathrm{x}$-axis in $\mathrm{ms}^{-2}$

$a_{\text {hwy }}=\mathrm{rms}$ weighted acceleration in $\mathrm{y}$-axis in $\mathrm{ms}^{-2}$

$a_{\text {hwz }}=$ rms weighted acceleration in z-axis in $\mathrm{ms}^{-2}$

Therefore the vector sum of vibration intensity is virtually independent of the orientation of the coordinate system.

The daily vibration exposure in terms of 8-h energy equivalent was derived from the magnitude of the vibration (vibration total value) and daily exposure duration. In order to facilitate comparison between daily exposures of different durations, the daily vibration exposure were expressed in terms of 8-h energy equivalent frequency-weighted vibration total value, $a_{h v}$ (eq.8 h) as shown in the equation 3.3 as follows

$\mathrm{A}(8)=a_{h v} \sqrt{T / T_{0}}$

Where

A (8) = Daily vibration exposure in terms of 8-h energy equivalent, in $\mathrm{ms}^{-2}$

$\mathrm{T}=$ Total daily duration exposure to the vibration $a_{h v}(\mathrm{~h}$ or sec)

$a_{h v}=$ Vibration total value in $\mathrm{ms}^{-2}$

$\mathrm{T}_{0}=$ Reference duration of $8 \mathrm{~h}(28,800 \mathrm{sec})$

The following formula was used to estimate exposure duration for finger blanching in 10 per cent of exposed persons as given in ISO5349 (2001).

$\mathrm{D}_{\mathrm{y}}=31.8[\mathrm{~A}(8)]^{-1.06}$

Where

$\mathrm{D}_{\mathrm{y}}=$ the group mean total (life time) exposure duration, in years.

A (8) = Daily vibration exposure in terms of 8-h energy equivalent, in $\mathrm{ms}^{-2}$

\section{Materials and Methods}

\section{Self-propelled Power Weeder}

A $5.5 \mathrm{hp} \mathrm{BCS} \mathrm{walk} \mathrm{behind} \mathrm{self-propelled}$ power weeder (Figure.2) manufactured in India and commonly used by the farmer was selected for the study. The power weeder is powered with single cylinder air-cooled horizontal petrol engine of $94 \mathrm{~kg}$ weight. Power weeder has $46 \mathrm{~cm}$ rotavator to carryout intercultural operations in different crops. The power transmission from the engine to the wheels and to the PTO is through a solid transmission in oil bath and there is a conical 
self-ventilating dry clutch. There was an adjustable handlebar, which can keep in 7 different positions to fit all types of operator. Handlebar mounted on silent-blocks to dampen vibrations and allow to use for several hours without straining the operator.

A commercially available Amar rotary tiller cum power weeder (Figure.3) was also selected. It is powered with $4.8 \mathrm{hp}$ greaves diesel engine of $46 \mathrm{~kg}$ weight. It is suitable for intercultural operations in row crops. Total weight of the power weeder is $140 \mathrm{~kg}$.

\section{Vibration Analyzer}

A SVAN 958, four channel vibration analyzer was used in this study (Figure.4). SVAN 958 analyzes the frequency range from $0.5 \mathrm{~Hz}$ to $20 \mathrm{kHz}$. Each of four channels work simultaneously with independently configured input (transducer type), filters, and RMS detector time-constants. The digital signal processor can execute advanced frequency analysis simultaneously to the meter mode for real-time four-channel $1 / 1$ octave or $1 / 3$ octave analysis including statistical calculations, real-time four-channel FFT analysis including cross spectra, and sound intensity measurements. Vibration analyzing accomplishes requirements according to ISO5349 (2001) and ISO-2631-1 (1997).

The vibration analyzer can measure vibration acceleration ranging from $17.8 \mathrm{~ms}^{-2}$ to $316 \mathrm{~ms}^{-}$ 2. A four-pin cable makes a connection between the accelerometer and the vibration analyzer. The data stored in the vibration analyzer was downloaded on a personal computer at the end of the experiment for further analysis.

\section{Hand adapter}

An adapter was used for attachment of transducer to measure the vibration intensity of hand-arm system. The adapter was made up of the aluminium alloy (Figure.5). A light weight tri-axial accelerometer was fixed by a stud in the adapter to measure hand-arm vibration. The design of the adapter was such that the accelerometer should lie in between the index and middle finger. The total weight of the adapter including the accelerometer was $28.8 \mathrm{~g}$.

The adapter was arranged according to the ISO-5349 (2001) on the handle bar of the power weeder. After arranging, the adapter should act as an integral part of the power weeder, so that it can sense the actual vibration levels as of the handle of the power weeder and there should not be any vibration dampening in between the adapter and handle. The adapter was arranged on the right hand handle bar of the power weeder.

\section{Tri-axial accelerometer}

One tri-axial accelerometer was used to measure vibration magnitude (Figure.6). The accelerometer was fastened by a stud in the adapter (Figure.7). The position of hand on the handle bar was such that it followed the directions according to the ISO standard.

\section{Tachometer}

A contact type tachometer was used to measure the rotation speed of an engine. The device displays the engine speed in terms of revolutions per minute (rpm) on an analog display. The tachometer was put on the center shaft of flywheel and the engine speed was set at 2200 and $2800 \mathrm{rpm}$ with the help of different accelerator level.

\section{Plan of Experiments for Measurement of Vibration magnitudes}

The field experiments were conducted at the different operational conditions. The selection 
of operational conditions and its level was based on review and the knowledge about the scenario of power weeder use. The different operating conditions and the measured parameters are given as below:

\section{Results and Discussion}

From the above observations, it was known that the HTV is very much higher in amar power weeder. The main reason behind this was the design. Both power weeders were designed very differently. Amar power weeder was of fully iron material including wheels also. It was heavier as compared to BCS power weeder. All covering parts of BCS power weeder were made of plastic. It has rubber tyres to reduce the vibration. Source of power also diesel engine for amar power weeder. This may also one of the reasons. Hence, BCS power weeder is better to use.

Table.1 Operating conditions independent variables

\begin{tabular}{|c|l|c|}
\hline S. No. & Source of variation & Levels \\
\hline $\mathbf{1}$ & $\begin{array}{l}\text { Operational conditions } \\
\text { (Transportation and weeding) }\end{array}$ & 2 \\
\hline $\mathbf{2}$ & $\begin{array}{l}\text { Engine speed } \\
(2200 \text { and } 2800 \mathrm{rpm})\end{array}$ & 2 \\
\hline
\end{tabular}

Table.2 Design of experiments dependent variables

\begin{tabular}{|l|l|c|l|}
\hline S. No. & Treatments & Levels & Particulars \\
\hline $\mathbf{1}$ & Operational conditions & 2 & $\begin{array}{l}\mathrm{X}=\text { Transportation }(\text { On bitumen road }) \\
\text { Y = Weeding }\end{array}$ \\
\hline $\mathbf{2}$ & Engine speed $(\mathrm{rpm})$ & 2 & $\begin{array}{l}\text { A =Half throttle speed }(2200 \mathrm{rpm}) \\
\mathrm{B}=3 / 4^{\text {th }} \text { throttle speed }(2800 \mathrm{rpm})\end{array}$ \\
\hline & Replication & 3 & \\
\hline
\end{tabular}

Table.3 Mean values of vibration magnitude $\left(\mathrm{ms}^{-2}\right)$ for engine speed and different operational conditions in Amar power weeder

\begin{tabular}{|c|c|c|}
\hline Operational conditions & \multicolumn{2}{|c|}{ Engine speed(RPM) } \\
\cline { 2 - 3 } & $\mathbf{2 2 0 0}$ & $\mathbf{2 8 0 0}$ \\
\hline Transportation & 13.37 & 14.1 \\
\hline Weeding & 16.75 & 17.55 \\
\hline Mean & 15.06 & 15.825 \\
\hline
\end{tabular}

Table.4 Mean values of vibration magnitude $\left(\mathrm{ms}^{-2}\right)$ for operational conditions and different engine speed in Amar power weeder

\begin{tabular}{|c|c|c|}
\hline Engine speed (RPM) & \multicolumn{2}{|c|}{ Operational conditions } \\
\cline { 2 - 3 } & Transportation & Weeding \\
\hline $\mathbf{2 2 0 0}$ & 13.37 & 16.75 \\
\hline $\mathbf{2 8 0 0}$ & 14.1 & 17.55 \\
\hline Mean & 13.74 & 17.15 \\
\hline
\end{tabular}


Table.5 Mean values of vibration magnitude $\left(\mathrm{ms}^{-2}\right)$ for engine speed and different operational conditions in BCS power weeder

\begin{tabular}{|c|c|c|}
\hline \multirow{2}{*}{ Operational conditions } & \multicolumn{2}{|c|}{ Engine speed(RPM) } \\
\cline { 2 - 3 } & $\mathbf{1 8 0 0}$ & $\mathbf{2 7 0 0}$ \\
\hline Transportation & 2.83 & 3.32 \\
\hline Weeding & 4.85 & 5.28 \\
\hline Mean & 3.84 & 4.3 \\
\hline
\end{tabular}

Table.6 Mean values of vibration magnitude $\left(\mathrm{ms}^{-2}\right)$ for operational conditions and different engine speed in BCS power weeder

\begin{tabular}{|c|c|c|}
\hline \multirow{2}{*}{ Engine speed (RPM) } & \multicolumn{2}{|c|}{ Operational conditions } \\
\cline { 2 - 3 } & Transportation & Weeding \\
\hline $\mathbf{1 8 0 0}$ & 2.83 & 4.85 \\
\hline $\mathbf{2 7 0 0}$ & 3.32 & 5.28 \\
\hline Mean & 3.075 & 5.065 \\
\hline
\end{tabular}

Fig.1 Coordinate system for hand
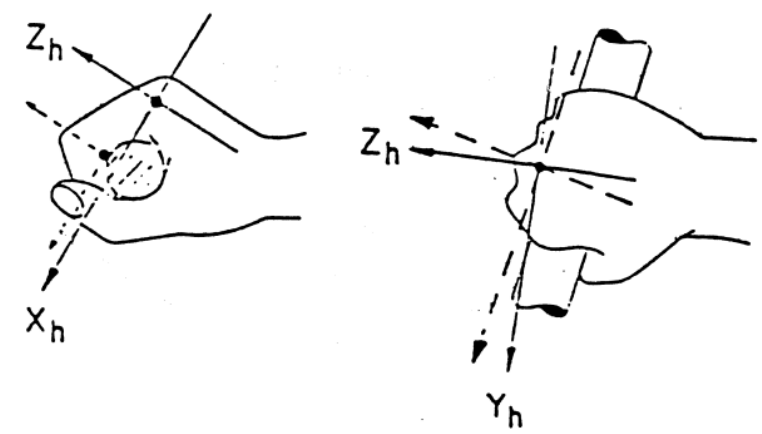

Basicentric coordinate system Biodynamic coordinate system

Fig.2 BCS power weeder

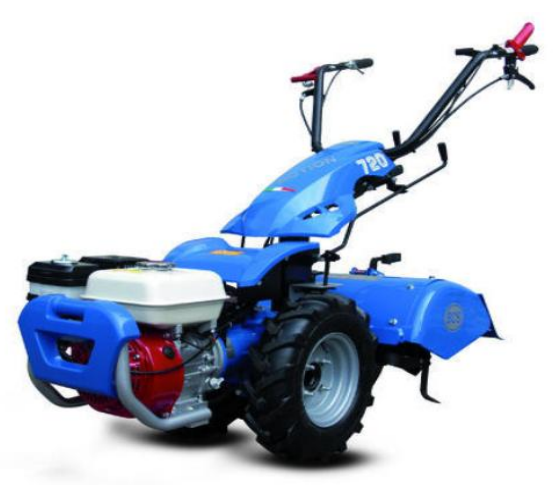


Fig.3 Amar power weeder

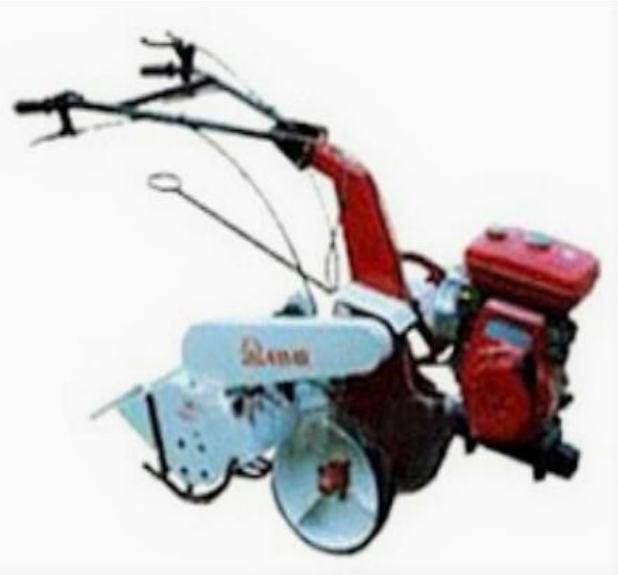

Fig.4 Vibration analyser

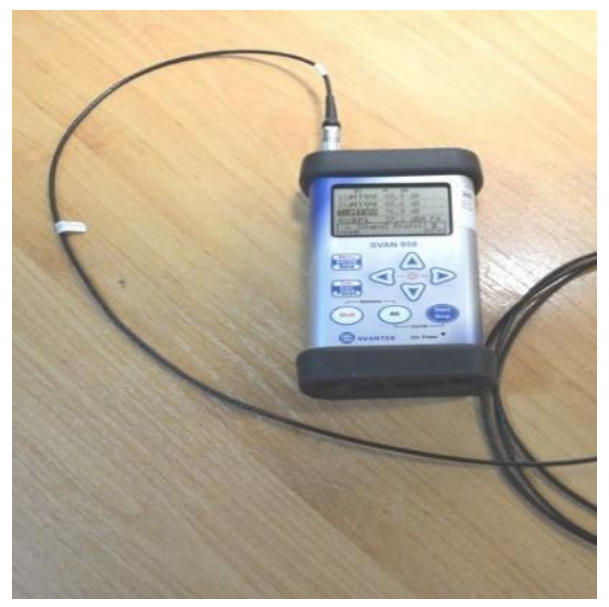

Fig.5 Hand adapter

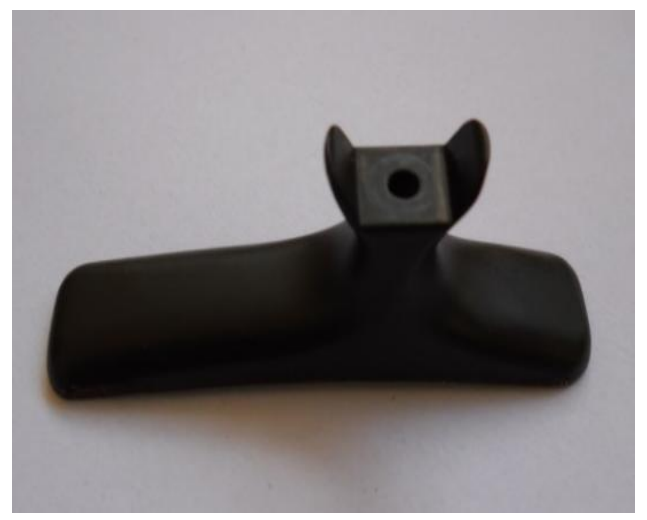


Fig.6 Accelerometer

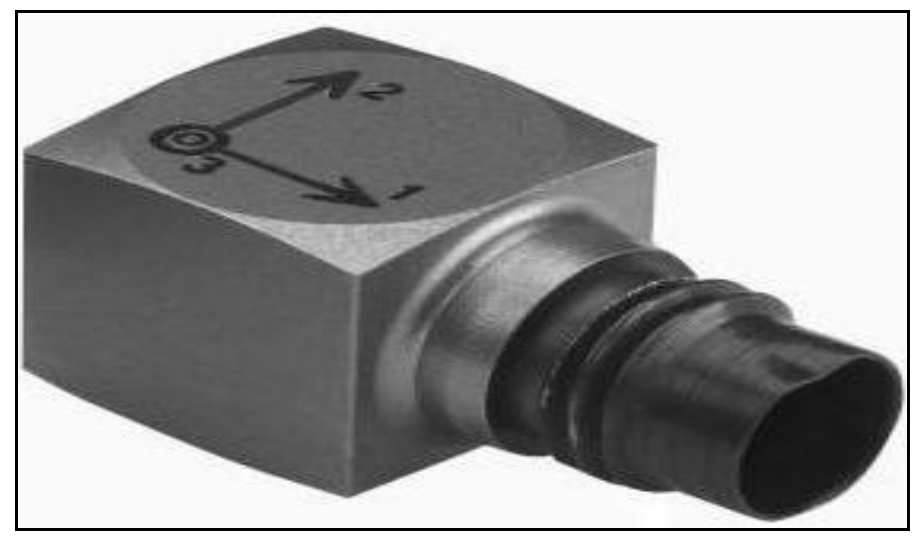

Fig.7 Accelerometer fixed by stud in adapter

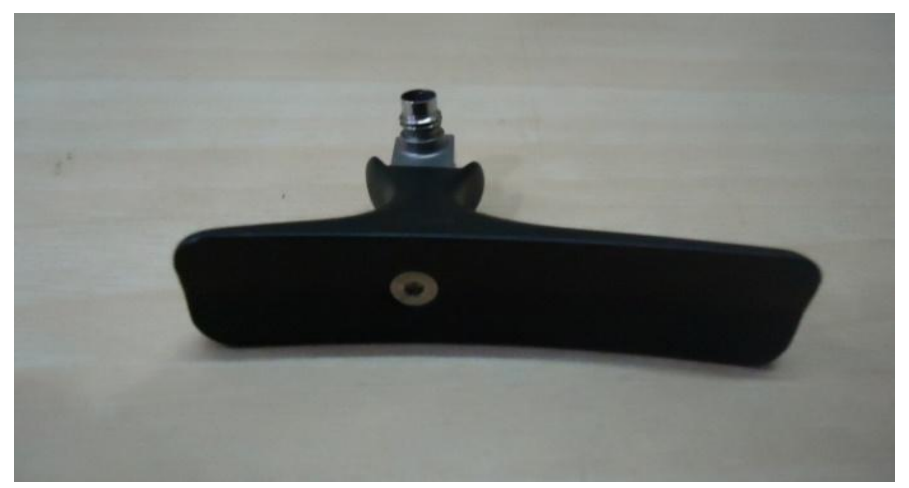

In conclusion this higher values of HTV were produced by all the iron metal parts, heavy weight if machine and iron wheels. Therefore, it will be better to reduce heavy weight and to use any mechanical measures to reduce the vibrations produced by engine like isolators or rubber interventions between the contact surfaces at the time of designing.

\section{References}

Abrams, C.F., and Suggs, C.W., 1969. Chain saw vibration: Isolation and transmission through the human arm. Transactions of the ASAE4: 423-425.

Araya, K., 1986. Handle vibration in hand operated tilling machines and tractors. Journal of the Japanese Society of Agricultural Machinery 48: 99-102.

Binisam and Kathirvel, K. 2009. Development and evaluation of vibration isolators for reducing hand transmitted vibration of walking and riding type power tiller. Biosystems Engineering 103: 427-437.

Chaffin, B.D. and Andersson, B.G. 1990. Occupational Biomechanics (2 $2^{\text {nd }}$ Ed.). John Wiley \& Sons. Inc. New York.

Dong, M.D. 1996. Testing analysis and evaluation of vibration transmitted by handles of GN-5 walking tractor. Journal of Zhejiang Agricultural University22: 68-72.

Fransson, C.N. and Winkel, J. 1991. Hand strength: The influence of grip spans and grip type. Ergonomics 34: 881-882.

Gite, L.P. and Singh, G. 1997. Ergonomics in Agricultural and Allied Activities in India. Technical Bulletin No. CIAE/97/70. Central Institute of Agricultural Engineering, Bhopal, India.

Grandjean, E. 1982. Fitting the Task to the Man 
- an Ergonomic Approach. Taylor\& Francis Ltd, London, pp. 77-81.

Gururaj, T.R. 2015. Development and evaluation of anti-vibrational measures for reducing Hand transmitted vibration in walking type self-propelled vertical conveyor reaper. M. Tech. thesis submitted to Maharana Pratap University of Agricultural and Technology, Udaipur, Rajasthan.

Harris, C.M. and Crede, C.E. 1976. Shock and Vibration Handbook. Mc Graw Hill Book Company, New York, pp. 132.

Harsha Nag, R. 2018. Performance evaluation of anti-vibration measures for reducing hand transmitted vibration in selfpropelled vertical conveyor reaper. $\mathrm{M}$. Tech. thesis submitted to Maharana Pratap University of Agriculture and Technology, Udaipur, Rajastan.

Huang, B. K. and Suggs, C. W. 1968. Tractor noise and operator performance. Transactions of ASAE: 1-5.

Ikeda, k., Ishizuka, A., Sawada and Urushiyama. 1998. Vibration acceleration magnitudes of hand-held tools and work pieces. Industrial health36: 197208.

ISO 2631. 1997. Mechanical vibration and shock- Evaluation of human exposure to whole-body vibration, Geneva, Switzerland.

ISO 5349. 1986. Mechanical vibrationGuidelines for the measurement and the assessment of human exposure to hand transmitted vibration, Geneva, Switzerland.

ISO 5349-1. 2001. Mechanical vibrationMeasurement and evaluation of human exposure to hand transmitted vibration, part 1: General requirements, Geneva, Switzerland.

ISO 5349-2. 2001. Mechanical vibrationMeasurement and evaluation of human exposure to hand transmitted vibration, part 2: Practical guidance for measurement at workplace, Geneva, Switzerland.

Jiao, Q., Shiliang, D. and Chunliang, J. 1989.
The dynamic characteristics of a walking tractor. Transactions of the Chinese Society of Agricultural-Machinery20: 3-8. Jiao Q., Wang Qianhua, Chen Kuifu and Zhao Daxing. 1993. The excitations and characteristics of the vibration of walking tractors handle using isolators. Transactions of the Chinese Society of Agricultural Machinery24: 74-79.

Kathirvel, K. and Binisam. 2006. Vibration characteristics of walking and riding type power tillers. Biosystem Engineering95: 517-528.

Keshavulu, Patil, B.P., Raghavendra, V. and Khan, S. 2017. Performance evaluation of wet land power weeder for paddy. Asian Journal of Agricultural Extension, Economics \& Sociology 18: 1-8.

Kroemer, K.H.E. and Grandjean, E. 2000. Fitting the Task to the Human, A Textbook of Occupational Ergonomics ( $5^{\text {th }}$ Ed.). Taylor \& Francis Ltd., UK.

Mc Ardle, D.E., Katch, F.I. and Katch, V.L. 1994. Essentials of Exercise Physiology. Lea \& Febiger, A waverly company, Philadephia, pp. 508.

Mc Ardle, W.D., Katch, F.I. and Katch, V.L. 2001. Exercise Physiology ( ${ }^{\text {th }}$ Ed.). Lippincott Willams and Wilkins publication.

Mirbod, S.M., Inaba R. and Iwata, H. 1994. Operating hand-held vibrating tools and prevalence of white fingers. Nagoya Journal of Medical Science 57: 173-183.

Mehta, C.R., Chandel, N.S., Senthilkumar, T. and Kanchan K.S. 2014. Trends of agricultural mechanization in India, CSAM Policy Brief.

Monalisha Sahu and Goel, A.K. 2017. Development of a Multipurpose Power Weeder. The International Journal of Social Sciences and Humanities Invention4: 3527-3531.

Nigg, B.M. and Hezog, W. 1999. Biomechanics of the musculoskeletal system ( $2^{\text {nd }} E d$.). John Wiley and Sons, New York, pp. 156.

Pandey, S., Verma, A.K. and Sirmour, A. 2019. Ergonomical studies on single row power weeder for rice crop. Journal of Crop and 
Weed 15: 145-150.

Punjabi, M.M., Anderson, G.B.J., Jorneus, L., Huly E.and Maltson L. 1986. In vivo measurement of spinal column vibrations. J Bone Joint [Am]68A: 695-701.

Pyykko, I., Farkkila, O., Starck, M., Aatola, J. and Jantti, V. 1976. Vibration syndrome among Finnish forest workers. Scandinavian Journal of Work, Environment \& Health12: 307-312.

Ragni, L., Vassalini, F., Xu, F. and Zhang, L. B. 1999. Vibration and noise of small implements for soil tillage. Journal of Agricultural Engineering Research74: 403-409.

Ramani Ranjan Pradhan, Santosh Kumar Mohanty, Aswini Kumar Goel and Debaraj Behera. 2019. Effect of hand arm vibration on operator during power weeder operation in paddy field. International Journal of Chemical Studies7: 920-926.

Rangasamy, K., Balasubramanian, M. and Swaminuthan, K.R. 1993. Evaluation of Power Weeder Performance. American Medical Association24: 16-18.

Rodahl, K. 1989. The Physiology of Work. Taylor and Francis, London, 51-79.

Sanders and Mc. Cormic. 1993. Human Factors in Engineering and Design ( $7^{\text {th }}$ Ed.). $M c$ Graw Hill, Inc., New York.

Sharma, A.P. and Jain, M.L. 1984. Vibration control in agricultural machinery. American Medical Association 15: 47-49.

Sravan Kumar, Ch. 2011. Modification and performance evaluation of ANGRAU power weeder developed by FIM scheme for paddy under SRI cultivation. M. Tech. thesis submitted to Acharya N. G. Ranga Agricultural University, Bapatla, Andhra Pradesh.
Suryakantha Khadai, Ashok Tripathi, Virendra Kumar, Anish Kumar and Surendra Pal. 2018. Ergonomic evaluation and comparison of existing and modified power weeder. International Journal of Current Microbiology and Applied Sciences7: 2476-2481.

Thambidurai, S., Kathirvel, K., Ramesh, D. and Jesudas, D.M. 2007. Vibration characteristics of self-propelled power weeders. Developments in Agricultural and Industrial Ergonomics 1: 241-249.

Varun Chaturvedi, Adarsh kumar and Singh, J.K. 2012. Power tiller vibration magnitudes and intervention development for vibration reduction. Applied Ergonomics43: 891-901.

Vivek, D.R., Deshmukh, B.D. and Dinesh, D. 2013. Review paper on various aspects of weeders for economical cultivation. International Journal of Modern Engineering Research3: 3296-3299.

Tewari, V. K., Dewangan, K.N. and Karmakar, S. 2004. Operator's fatigue in field operations of hand tractors. Biosystems Engineering 89: 1-11.

Tewari, V.K., Dewangan, K.N., Sarkar, B., Vidhu, K.P. and Patel, T. 2005. Reduction of vibration in self- propelled vertical conveyor reaper. International Ergonomics Conference on HWWE, IITG 1055-1059.

Waersted, M. and Westgaard, R.H. 1991. Working hours as a risk factor in the development of musculoskeletal complaints. Ergonomics34: 265-276.

Ying, Y., Zhang, L., Xu, F. and Dong, M. 1998. Vibratory characteristics and hand transmitted vibration reduction of walking tractor. Transactions of the ASAE41: 917922.

\section{How to cite this article:}

Leela Jyothi, S., S. S. Meena and Tiwari, G. S. 2021. Comparative Study of Two Different Types of Power Weeders. Int.J.Curr.Microbiol.App.Sci. 10(01): 613-622. doi: https://doi.org/10.20546/ijcmas.2021.1001.074 